\title{
Associations between frequency of tea consumption and health and mortality: evidence from old Chinese
}

\author{
Li Qiu ${ }^{1}$, Jessica Sautter ${ }^{2,3}$ and Danan Gu ${ }^{4 *}$ \\ ${ }^{1}$ Department of Neurobiology, Duke University, Durbam, NC 27710, USA \\ ${ }^{2}$ Department of Internal Medicine, Duke University Medical Center, Durham, NC 27708, USA \\ ${ }^{3}$ Center for Health Services Research in Primary Care, Durham VA Medical Center, Durham, NC 27708, USA \\ ${ }^{4}$ Department of Medicine, Duke University, 200 Trent Dr Busse BLDG RM 1506, Durbam, NC 27710, USA
}

(Submitted 14 July 2011 - Final revision received 16 November 2011 - Accepted 28 November 2011 - First published online 16 January 2012)

\section{Abstract}

Tea consumption may be associated with reduced risk of morbidity and mortality; however, this association is not conclusive and has rarely been investigated among very old adults. The present study examines how self-reported frequency of tea consumption in daily life is associated with health and mortality among very old adults in China. The data are from a national longitudinal data set that included 32606 individuals (13429 men and 19177 women) aged 65 years and older: 11807 respondents aged 65 to 84 years and 20799 respondents aged 85 years and older. A total of four measurements between 1998 and 2005 resulted in 51668 observations. Hazard regressions showed that men who drink tea almost every day have a 10-20\% lower risk of death compared to their counterparts who seldom drink tea, after adjusting for numerous confounders including baseline health. This relationship was stronger in younger male elders aged 65 to 84 years than in the oldest-old men aged 85 years and older. However, frequency of tea consumption was not significantly associated with mortality in women. Our analyses further show that high frequency of tea consumption is significantly associated with reduced OR of disability in activities of daily living, cognitive impairment, self-rated poor health, cumulative health deficits and CVD in both young elders and the oldest-old, and in both men and women. These results suggest that the health benefit of drinking tea is universal. We conclude that frequent tea consumption probably helps one achieve healthy longevity and that men benefit more from such lifestyles.

Key words: Tea consumption: China: Healthy longevity: Mortality: Sex differentials: Older adults: Oldest-old

Tea, which is generally consumed in the forms of green, oolong and black tea, is the most consumed beverage in the world after water ${ }^{(1)}$. There has been growing evidence in the literature to suggest that habitual consumption of tea probably produces some level of chemoprevention that prevents stroke, lung cancer, prostate cancer and breast cancer, and thus reduces cause-specific and all-cause mortality risk ${ }^{(2-7)}$. For example, one recent study focusing on 40000 Japanese adults aged 40 to 79 years found that green tea consumption is associated with a reduced risk of all-cause mortality and of mortality due to CVD among adults without history of stroke, coronary health disease or cancer at baseline ${ }^{(8)}$. A meta-analysis of nearly 200000 respondents from nine studies showed that, regardless of their country of origin and type of tea, individuals who frequently consume three cups or more of tea per day have a $21 \%$ lower risk of stroke than thoseconsuming less than one cup per day ${ }^{(9)}$. Tea consumption may also improve mental performance ${ }^{(10)}$. However, the association between tea consumption and health is not conclusive; some studies found that frequent tea consumption does not protect against deaths due to stomach cancer ${ }^{(11)}$ and lung cancer ${ }^{(12)}$.

These findings have demonstrated that tea consumption is associated with health and have identified some mechanisms and diseases through which tea consumption is associated with subsequent health and mortality. However, we know little about potential variation by age or sex in very old adults due to a limited number of studies and relatively small samples of the oldest-old, especially nonagenarians and centenarians who provide the best opportunities to study healthy longevity. Sex differences in associations between tea consumption and subsequent mortality/health have also been inadequately studied and the results are inconsistent. So far, only a few studies have demonstrated a sex difference in associations between tea consumption and cancer incidence or mortality. For example, one prospective study showed that among those

Abbreviations: ADL, activities of daily living; CLHLS, Chinese Longitudinal Healthy Longevity Survey; DI, deficit index; MMSE, Mini-Mental State Examination; SES, socio-economic status.

* Corresponding author: D. Gu, email gudanan@yahoo.com 
who consumed more than ten cups of green tea daily, women experienced a greater reduction in cancer incidence than men ${ }^{(13)}$. Furthermore, two large cohort studies demonstrated a decreased risk for the development of gastric and oral cancers among women, and not men, if individuals drink more than five cups daily ${ }^{(14,15)}$. However, it was found that men benefit more than women from consumption of green tea, in studies related to incidence of coronary artery diseases ${ }^{(16)}$ and renal cell cancer ${ }^{(17)}$. Similarly, other studies further showed that tea consumption could reduce mortality due to $\mathrm{CVD}^{(5)}$ and due to Parkinson's disease ${ }^{(18)}$ in men but not in women.

In mainland China (hereafter China), where tea has been consumed for more than 4000 years, there is a paucity of studies examining the association between tea consumption and mortality. With few exceptions ${ }^{(19)}$, no study has investigated the linkages between tea consumption and subsequent health/ mortality among old adults in China. It is unclear whether the empirical findings in Western countries will hold in China, where mortality rates are much higher than those of Western nations and the prevalence of tea consumption is higher. The aim of the present research is to investigate whether the frequency of tea consumption is associated with subsequent mortality and health condition, by using a nationally representative population-based survey data set from China with the largest sample of centenarians and nonagenarians in the current world. Because of the high rates of tea consumption in China and the world, small effects of tea consumption on mortality and health could have large implications for public health ${ }^{(20)}$.

\section{Data and methods}

\section{Data sources}

The data used in this study were derived from four waves of the Chinese Longitudinal Healthy Longevity Survey (CLHLS) in 1998, 2000, 2002 and 2005. This observational study was approved by the Institutional Review Board at Duke University Medical Center; all participants provided informed consent. The CLHLS was conducted in a randomly selected half of the counties and cities of twenty-two provinces in China. The CLHLS aimed to interview all centenarians in the sampled counties/cities. For each centenarian interviewed, one nearby octogenarian and one nonagenarian with pre-designated age and sex that were based on the centenarian's pre-designated random code were randomly chosen to be interviewed. The term 'nearby' refers to the same village or street, or the same town, county or city, where applicable. The primary purpose of this sampling strategy is to ensure comparable numbers of randomly selected male and female octogenarians and nonagenarians at each age from 80 to 99 years. Starting in 2002, the CLHLS extended its sample to cover elders aged 65 to 79 years. To ensure sufficient sample size in subsequent waves, the CLHLS recruited a new set of elders at each subsequent wave to replace those who were lost to follow-up or who died within survey intervals. The age and sex of each newly interviewed respondent at a subsequent wave was based on the person who was lost to follow-up or died within survey intervals. This replenishing design is a common practice in longitudinal surveys ${ }^{(21,22)}$. The total number of the respondents is 32606 with 51668 observations. The average length of follow-up for survivors from initial interview to the 2005 wave was about 3.5 years for younger-old adults aged 65 to 84 years and about 3.8 years for the oldest-old aged 85 years and older. The corresponding figures for the deceased persons were $2 \cdot 5$ years and $2 \cdot 1$ years.

The CLHLS collected data on frequency of tea consumption for each respondent, in addition to collecting a variety of data covering demographic characteristics, family and household characteristics, lifestyle, diet, psychological characteristics, economic resources, self-reported health, self-reported life satisfaction, lower and upper extremities performance, instrumental activities of daily living, activities of daily living (ADL), cognitive functioning and chronic disease. All information was obtained through in-home interviews. All interviews were performed by a well-trained enumerator or CLHLS research team member and a medical school student or a local doctor/nurse. If a respondent was unable to answer questions due to illness or cognitive limitations, the next-of-kin, a family member or a very close friend/caregiver served as a proxy to answer questions. More than $80 \%$ of CLHLS respondents did not use a proxy; respondents with full proxy accounted for less than $1 \%$ of the sample ${ }^{(23)}$. Studies have shown that proxy respondents can generate fairly accurate data on objective questions, and with good questionnaire designs can generate goodquality data on subjective questions ${ }^{(24)}$. The dates of death for the respondents who died between survey intervals were also collected either from officially issued death certificates whenever available or from next-of-kin and local Residential Committees in cases where such certificates were not available. This is the first nationwide longitudinal survey in China and the largest survey focusing on older adults conducted in China to date. Systematic assessments of data quality regarding accuracy of age-reporting, reliability, validity and consistency of numerous measures, and randomness of attrition show that the data quality of the CLHLS is high ${ }^{(23,25)}$.

\section{Frequency of tea consumption}

The CLHLS asked 'how often do you usually drink tea at present?' in each wave. There were three response categories: daily or almost daily (five times or more per week), some times (two to four times every week) and seldom or never (once a week or less). Notice that this measures frequency, not amount, of tea consumption. This measure is slightly different from some previous studies that quantify the amount of tea consumption in $\operatorname{cups}^{(8)}$.

\section{Health outcomes}

We focused on two broad sets of analyses. The first set of analyses focused on associations between tea consumption and subsequent mortality risk (abbreviated as tea-mortality association sample). Mortality risk is measured by the survival status at subsequent waves (i.e. survived or died) and the exposure time in each survey interval from 1998 to 2005.

\footnotetext{
intervals. This replenishing design is a common practice in
} 
The second set focused on associations between tea consumption and morbidity, which included several different health outcomes measured at each wave (abbreviated as teahealth association sample). These health outcome variables included disability in ADL, impairment in cognitive function, poor self-reported health, cumulative deficit index (DI) and suffering from CVD. ADL disability was measured with the Katz scale $^{(26)}$ and indicated whether a respondent needed help in performing any of six daily activities (bathing, dressing, eating, indoor movement, toileting and continence). Cognitive function was measured with the Chinese version of the Mini-Mental State Examination (MMSE) that tests four aspects of functioning: orientation, calculation, recall and language ${ }^{(27)}$. The Chinese version of the MMSE has been validated in studies and reflects the cultural and socio-economic conditions among the older adults in China and uses questions that participants with normal cognitive function can understand and answer ${ }^{(23,28,29)}$. Cognitive impairment was indicated by an MMSE score of less than 18 out of $30^{(29)}$. Self-reported health was designed in the CLHLS with five categories: very good, good, so-so, poor and very poor. We combined poor and very poor as one category and very good, good, and so-so as the other.

A cumulative health DI, which is normally defined as the unweighted count of the number of deficits divided by the total number of possible deficits for a given person, has received increasing attention recently ${ }^{(30,31)}$. Similar to established research ${ }^{(32-35)}$, we used thirty-nine indicators of selfreported health, cognitive functioning, disability, auditory and visual ability, depression, heart rhythm and numerous chronic diseases that were collected in the 2002 CLHLS. We dichotomised individual items and coded them as ' 1 ' when a deficit was present. Consistent with previous research ${ }^{(35)}$, we assigned a score of ' 2 ' if the respondent had a serious illness that caused him or her to be hospitalised or bedridden two or more times during the past 3 years. We then computed the DI by summing all deficits and dividing by the total number of possible deficits (range $=0-1$ ). The validity of the DI in the CLHLS data sets has been verified ${ }^{(33,36)}$. A list of detailed variables used to construct the DI has been published elsewhere ${ }^{(32,37)}$. Poor health was defined as the highest quintile of the DI. Thus, the health outcome is a dummy variable, with poor health coded as ' 1 ' and good health coded as ' 0 '. Ordinal classification or other categorisations of the DI only slightly altered the results. This set of analyses is also called the tea-health association. The inclusion of CVD is based on previous findings in the literature ${ }^{(2,5,6,8,9)}$. The selfreported CVD condition in the study refers to diagnoses by medical doctors at local hospitals.

\section{Covariates and confounders}

Following the guidelines and findings in the gerontology and epidemiology literature ${ }^{(38-42)}$, we controlled for numerous factors that were associated with mortality and health outcomes. Demographic variables included age, ethnicity (Han $v$. non-Han) and current residence (urban $v$. rural). Sex was a stratifying variable for separate analyses for men and women. Socio-economic status (SES) and family support included years of schooling ( 1 year or more $v .0$ years), economic status (economically independent $v$. dependent) and current marital status (married $v$. not married). Diet included eating vegetables almost daily at present (yes $v$. no), eating meat almost daily at present (yes $v$. no), eating fish almost daily at present (yes $v$. no) and eating garlic almost daily at present (yes $v$. no). Health practices were measured by smoking at present (yes $v$. no), heavy alcohol consumption at present (yes $v$. no) and regularly doing exercises at present (yes $v$. no). Heavy alcohol consumption was defined as consuming $200 \mathrm{~g}$ liquor or $400 \mathrm{~g}$ beer daily.

\section{Analytical strategies}

The tea-mortality association set of analyses was examined using a Weibull parametric hazard model adjusted for intrapersonal associations across waves. A Cox semi-parametric proportional hazard model was estimated first, but several variables in the model failed to meet the proportionality requirement. Thus, we applied the parametric model. Comparisons with the log-normal, log-logistic, exponential and Gompertz models showed that the Weibull model yielded the lowest Akaike information criterion index, which suggested that the Weibull model was the best fit. Survival time was entered as days from the date of the initial interview to the date of the 2005 interview for survivors and time from the initial interview to the date at death for each respondent who died before the 2005 wave. From 1998 to 2005, there were 12384 deaths in total: 7551 women and 4833 men.

In multi-wave survival analyses, we dropped those observations if one's survival status was unknown in a subsequent interview. The total valid number of person-records for this set of tea-mortality analyses is 31643 observations (18445 for women and 13198 for men) from 21892 respondents (12780 women and 9112 men).

Six models were constructed to investigate how frequency of tea consumption is associated with mortality. Model I included four demographic variables of age, sex, ethnicity and urban-rural residence in addition to frequency of tea consumption. Model II added dietary variables into Model I. Model III further added health practice into Model II. Model IV added SES and marital status into Model II. Model V added SES and marital status into Model III; and Model VI additionally added health condition at previous wave into Model V. These model design strategies are a common practice in research on ageing ${ }^{(39,42)}$.

For the tea-health association, we applied multi-wave logistic regressions. The multi-wave logistic regression differs from conventional logistic regression by adjusting for intrapersonal correlations across waves; this is a type of multilevel analysis, or growth curve model. We included all respondents at each wave for multi-wave logistic regressions because only about 1000 respondents had four waves of data points. Within this strategy, some respondents had four data points, while some had two or three points and others had only one. This is an example of an unbalanced data design ${ }^{(43)}$. The advantage of the design allows us to have a large sample size, 
while it still captures major trajectories of study variables ${ }^{(44)}$. The total number of valid person-records for this set of analyses is 51668 for 32606 respondents.

The rates of missing values for all independent variables and controls in the two sets of analyses are less than $5 \%$. To reduce the influence of missing values on the modelling outcomes, we used a multiple-imputation approach based on ten random multiple-imputed replicates to fill in missing values $^{(44)}$. An alternative approach, which used the mode of the corresponding missing variables to impute the missing values as suggested in the literature ${ }^{(45)}$, was applied as well; it did not alter the results at all. In the tea-health association analyses, we controlled for all covariates simultaneously to investigate whether frequency of tea consumption is associated with five health outcomes.

Given that the sampling weight variable in the publicly released CLHLS data sets was calculated based on the age-sex-urban-rural residence-specific distribution of the population and does not capture other important compositional variables (e.g. marital status, economic status), this weight was not applied in the present study. Research has shown that including variables related to sample selection produces unbiased coefficients without weights ${ }^{(46)}$. Our preliminary analyses confirmed that the overall patterns and conclusions were similar in the weighted and unweighted data. Because men and women and young elders aged 65 to 84 years and the oldest-old aged 85 years and older have different trajectories of health deterioration and mortality risk, all analyses were performed for men and women and for young elders aged 65 to 84 years and the oldest-old aged 85 years and older separately using STATA version 10.1

\section{Results}

Table 1 presents the distribution of covariates for the teahealth association for both women and men by two broad age groups. The distribution for the tea-mortality association sample is similar, and hence we did not present the same here. Table 2 presents the distribution of frequency of tea consumption by covariates from the tea-health association sample. The distributions from the tea-mortality association sample are similar and are thus not presented. The observed relative frequencies in Table 2 show that oldest-old age, living in a rural area, non-Han ethnicity, low SES, single marital status, poor health, diet rich with meat, fish, garlic and vegetables, nonsmoking, low alcohol consumption and lack of exercise at present are associated with a lower proportion of frequent tea consumption as compared to their counterparts, respectively. Old men tend to have a higher proportion of frequent tea consumption than old women.

\section{Frequency of tea consumption and mortality}

Table 3 shows that, among young elders aged 65 to 84 years, men who drink tea sometimes (2-4 cups/week) have $19 \%$ lower mortality risk as compared to men who seldom drink tea. This association does not change regardless of the presence of various confounders. The beneficial effect of consuming tea sometimes on mortality risk is not significant among the oldest-old men and among both young and oldest-old women.

Table 3 also demonstrates that, compared to young elderly men aged 65 to 84 years who seldom drink tea, same-aged men who drink tea almost every day have $12-23 \%$ lower mortality risk depending on the presence of different covariates. These associations are all significant at $P=0.05$ except one that is significant at $P=0 \cdot 10$ (i.e. $12 \%$, see Model VI in the middle panel) when the overall health condition at the previous wave is controlled for. Unlike the case for consuming tea sometimes, the beneficial effect on mortality for almostdaily tea consumption is significant among the oldest-old men aged 85 years and older. The reduced mortality hazard for almost-daily tea consumption ranges from 6 to $16 \%$ in the presence of different confounders in the oldest-old. With one exception, all relative hazard ratios are significant at $P=0 \cdot 05$. However, similar to the results for consuming tea sometimes, we did not find a protective association with mortality for almost-daily tea consumption among women. The results in Table 3 further show that, with few exceptions, there is no significant mortality advantage associated with almost-daily tea consumption compared to drinking tea only sometimes.

\section{Frequency of tea consumption and health}

Table 4 presents the OR for the association among frequency of tea consumption, and general health condition (being ADL disabled, cognitively impaired, in self-rated poor health, and one in poor overall health) and one specific condition (i.e. CVD). The results reveal that, in most cases, consuming tea sometimes or almost daily is associated with substantially reduced odds of being in a poor health status for both men and women and for both young elders and the oldest-old, after controlling for numerous confounders. In some cases, the reductions can reach nearly $50 \%$ (e.g. for men in the age group 65-84 years, almost-daily tea consumption compared to seldom drinking tea). Overall, reductions are greater in men than in women for both age groups; however, there is no consistent age pattern. Drinking tea at a frequency of almost daily (compared to seldom or never) was associated with a $37 \%$ decrease in the risk of suffering from CVD in young elderly men and a $50 \%$ decrease in young elderly women. The oldest-old men who drink tea almost daily have $27 \%$ lower odds of suffering from CVD as compared to those oldest-old who seldom or never drink tea. This protective effect of tea consumption on CVD is not significant in oldest-old women. We further explored the associations between tea consumption and visual and hearing functions (results not shown) and found that tea consumption was also associated with reduced risk of suffering from hearing impairment, especially in men. However, frequency of tea consumption had no significant relationship with visual impairment in both men and women and in both the young elderly and oldest-old population. 
Table 1. Distributions of the covariates: tea-health sample*

(Number of observations and percentages; mean values and standard deviations)

\begin{tabular}{|c|c|c|c|c|}
\hline & \multicolumn{2}{|c|}{ Age $65-84$ years } & \multicolumn{2}{|c|}{ Age $85+$ years } \\
\hline & Women ( $n$ 8836) & Men (n 9215) & Women (n 21115) & Men ( $n$ 12502) \\
\hline \multicolumn{5}{|l|}{ Frequency of tea consumption } \\
\hline Seldom (\%) & $56 \cdot 9$ & $38 \cdot 1$ & $62 \cdot 4$ & $46 \cdot 9$ \\
\hline Sometimes (\%) & $18 \cdot 6$ & $19 \cdot 2$ & $17 \cdot 6$ & $20 \cdot 0$ \\
\hline Almost daily (\%) & 24.5 & $42 \cdot 7$ & $20 \cdot 0$ & $33 \cdot 1$ \\
\hline \multicolumn{5}{|l|}{ Socio-demographic characteristics } \\
\hline Mean age (years) & $76 \cdot 5$ & $76 \cdot 5$ & $95 \cdot 8$ & $92 \cdot 8$ \\
\hline Urban residence (\%) & $48 \cdot 2$ & $49 \cdot 2$ & $46 \cdot 2$ & $48 \cdot 3$ \\
\hline Han ethnicity (\%) & 94.0 & $95 \cdot 0$ & $93 \cdot 3$ & $93 \cdot 6$ \\
\hline $1+$ years of schooling (\%) & $27 \cdot 8$ & $72 \cdot 5$ & $12 \cdot 6$ & $59 \cdot 5$ \\
\hline Economically independent (\%) & $21 \cdot 0$ & $43 \cdot 2$ & $5 \cdot 3$ & $29 \cdot 0$ \\
\hline Married (\%) & $37 \cdot 0$ & $66 \cdot 3$ & 3.9 & $29 \cdot 4$ \\
\hline \multicolumn{5}{|l|}{ Dietary } \\
\hline Eat vegetables almost daily (\%) & $62 \cdot 6$ & $63 \cdot 3$ & $56 \cdot 8$ & $58 \cdot 6$ \\
\hline Eat meat almost daily (\%) & $31 \cdot 8$ & $40 \cdot 6$ & $32 \cdot 8$ & $37 \cdot 8$ \\
\hline Eat fish almost daily (\%) & $19 \cdot 4$ & $22 \cdot 7$ & $16 \cdot 2$ & $18 \cdot 9$ \\
\hline Eat garlic almost daily (\%) & $18 \cdot 1$ & 24.4 & $12 \cdot 2$ & $15 \cdot 8$ \\
\hline \multicolumn{5}{|l|}{ Health practices } \\
\hline Current regular exerciser (\%) & $34 \cdot 7$ & $46 \cdot 3$ & $19 \cdot 1$ & $36 \cdot 3$ \\
\hline Current smoker (\%) & $9 \cdot 2$ & $40 \cdot 8$ & $6 \cdot 6$ & $26 \cdot 8$ \\
\hline Current alcohol drinker (\%) & $10 \cdot 6$ & $35 \cdot 7$ & $13 \cdot 9$ & $28 \cdot 7$ \\
\hline \multicolumn{5}{|l|}{ Health conditions } \\
\hline ADL disabled (\%) & $11 \cdot 6$ & $10 \cdot 4$ & $47 \cdot 7$ & $32 \cdot 6$ \\
\hline Cognitively impaired (\%) & $6 \cdot 6$ & 4.5 & $42 \cdot 3$ & $23 \cdot 7$ \\
\hline Self-reported poor health (\%) & $17 \cdot 0$ & $14 \cdot 3$ & $26 \cdot 6$ & $19 \cdot 8$ \\
\hline Mean of the deficits index & $0 \cdot 17$ & $0 \cdot 15$ & 0.29 & 0.23 \\
\hline Suffering from CVD (\%) & 5.5 & $7 \cdot 0$ & 3.4 & 4.5 \\
\hline \multicolumn{5}{|l|}{ Deathst } \\
\hline$\%$ & $16 \cdot 8$ & $19 \cdot 5$ & $50 \cdot 1$ & $48 \cdot 3$ \\
\hline$n$ & 4864 & 5194 & 13581 & 8004 \\
\hline \multicolumn{5}{|c|}{$\begin{array}{l}\text { Average length of follow-up for survivors } \\
\text { from initial interview to the } 2005 \\
\text { interview (years) } \ddagger\end{array}$} \\
\hline Mean & 3.49 & 3.44 & 3.83 & 3.77 \\
\hline SD & 1.29 & 1.23 & 1.61 & 1.64 \\
\hline \multicolumn{5}{|c|}{$\begin{array}{l}\text { Average length of follow-up for the } \\
\text { deceased respondents from initial interview to } \\
\text { the date of death (years) } \ddagger\end{array}$} \\
\hline Mean & $2 \cdot 53$ & $2 \cdot 45$ & $2 \cdot 03$ & $2 \cdot 12$ \\
\hline SD & 1.62 & 1.62 & 1.48 & 1.57 \\
\hline
\end{tabular}

ADL, activities of daily living.

* The distribution in the table is based on the tea-health association data set unless otherwise stated.

†This is based on the tea-mortality association data set that excluded those lost to follow-up during the interval between two consecutive surveys.

$\ddagger$ In calculating the average length of follow-up for survivors, those who were lost to the follow-up were excluded, but their earlier survival information after the initial interview was included whenever available. The shorter average length of follow-up among the elders aged 65-84 years is primarily because the 1998 wave did not collect data for those aged $65-79$ years.

\section{Discussion}

In the present study, we investigated the associations between frequency of tea consumption and subsequent health and mortality by age and sex based on a large population-based longitudinal survey with a large sample size for very old persons in China. To our knowledge, this study was among the first to use nationally representative data to examine the associations between frequency of tea consumption and subsequent mortality among exceptionally long-living persons and to look at age and sex differentials in these associations. We show that tea consumption is associated with improved men's survivorship at old ages, but frequency of tea consumption is not significantly associated with women's survivorship at old ages. However, frequency of tea consumption is associated with better health status for both men and women, including reduction in odds of self-reported CVD. These findings not only are consistent with earlier studies, but also extend the previous findings that mainly focus on non-elders.

It has been recognised in the literature that the health or survival benefits of tea consumption are related to flavonoids ${ }^{(47)}$, a group of polyphenols with considerable antioxidant power that have various anticarcinogenic effects, inhibit nitrosation and cell proliferation that protect colonic cell membranes from free-radical damage, regulate cell growth and apoptosis, and promote detoxifying enzymes ${ }^{(48)}$. Flavonoids may also exert anti-inflammatory effects ${ }^{(50)}$ and inhibit tumorigenesis ${ }^{(51)}$. A number of experimental studies have shown that phytochemicals may be another element in tea that 
NS British Journal of Nutrition

Table 2. Distributions of the frequency of tea consumption by the covariates: tea-health sample

\begin{tabular}{|c|c|c|c|c|c|c|c|c|}
\hline & \multicolumn{4}{|c|}{ Women } & \multicolumn{4}{|c|}{ Men } \\
\hline & Seldom (\%) & Sometimes (\%) & Almost daily (\%) & Total observations & Seldom (\%) & Sometimes (\%) & Almost daily (\%) & Total observations \\
\hline \multicolumn{9}{|l|}{ Socio-demographics } \\
\hline \multicolumn{9}{|l|}{ Age groups } \\
\hline Younger-old aged $65-84$ years & $56 \cdot 9$ & $18 \cdot 6$ & 24.5 & 8836 & 38.1 & $19 \cdot 2$ & $42 \cdot 7$ & 9215 \\
\hline Oldest-old aged $85+$ years & 62.4 & $17 \cdot 6$ & $20 \cdot 0$ & 21115 & 46.9 & $20 \cdot 0$ & 33.1 & 12502 \\
\hline \multicolumn{9}{|l|}{ Residence } \\
\hline Rural & $62 \cdot 4$ & 18.4 & $19 \cdot 2$ & 15932 & $46 \cdot 4$ & $21 \cdot 3$ & $32 \cdot 3$ & 11145 \\
\hline Urban & $58 \cdot 9$ & 17.4 & 23.7 & 14019 & 39.6 & $18 \cdot 1$ & $42 \cdot 3$ & 10572 \\
\hline \multicolumn{9}{|l|}{ Ethnicity } \\
\hline Minorities & $76 \cdot 2$ & 11.0 & $12 \cdot 8$ & 1952 & $64 \cdot 0$ & $15 \cdot 7$ & $20 \cdot 3$ & 1260 \\
\hline Han & 59.7 & $18 \cdot 4$ & 21.9 & 27999 & 41.8 & $20 \cdot 0$ & 38.2 & 20457 \\
\hline \multicolumn{9}{|l|}{ Education } \\
\hline No education & $62 \cdot 2$ & $17 \cdot 8$ & $20 \cdot 0$ & 24828 & $49 \cdot 8$ & $20 \cdot 8$ & 29.4 & 7596 \\
\hline $1+$ years schooling & 53.9 & $18 \cdot 7$ & $27 \cdot 4$ & 5110 & 39.5 & $19 \cdot 7$ & $37 \cdot 2$ & 14121 \\
\hline \multicolumn{9}{|l|}{ Economic status } \\
\hline Not independent & $61 \cdot 5$ & $17 \cdot 9$ & $20 \cdot 7$ & 26985 & $46 \cdot 5$ & $21 \cdot 0$ & 32.5 & 14120 \\
\hline Independent & $54 \cdot 3$ & $18 \cdot 3$ & $27 \cdot 4$ & 2966 & 36.9 & 17.4 & $45 \cdot 7$ & 7597 \\
\hline \multicolumn{9}{|l|}{ Marital status } \\
\hline Not-married & 61.4 & $17 \cdot 8$ & $20 \cdot 8$ & 25869 & $45 \cdot 5$ & $20 \cdot 3$ & $34 \cdot 2$ & 11935 \\
\hline Married & $56 \cdot 6$ & 18.5 & 24.9 & 4082 & $40 \cdot 2$ & $19 \cdot 0$ & 40.8 & 9782 \\
\hline \multicolumn{9}{|l|}{ Diet } \\
\hline \multicolumn{9}{|c|}{ Eat vegetables almost daily at present } \\
\hline No & 64.4 & $18 \cdot 7$ & $16 \cdot 9$ & 12425 & $47 \cdot 2$ & $22 \cdot 3$ & 30.6 & 8565 \\
\hline Yes & $58 \cdot 2$ & $17 \cdot 3$ & 24.5 & 17526 & $40 . \overline{5}$ & $18 \cdot 0$ & 41.5 & 13152 \\
\hline \multicolumn{9}{|l|}{ Eat meat almost daily at present } \\
\hline No & $62 \cdot 4$ & $18 \cdot 7$ & $19 \cdot 0$ & 20204 & $46 \cdot 8$ & 21.9 & 31.3 & 13257 \\
\hline Yes & $57 \cdot 4$ & $16 \cdot 4$ & $26 \cdot 2$ & 9747 & 37.4 & $16 \cdot 3$ & $46 \cdot 4$ & 8460 \\
\hline \multicolumn{9}{|l|}{ Eat fish almost daily at present } \\
\hline No & 62.4 & $18 \cdot 3$ & $19 \cdot 4$ & 24835 & 45.4 & 20.9 & 33.7 & 17259 \\
\hline Yes & 53.0 & $16 \cdot 2$ & $30 \cdot 8$ & 5117 & 34.3 & $15 \cdot 2$ & 50.5 & 4458 \\
\hline \multicolumn{9}{|l|}{ Eat garlic almost daily at present } \\
\hline No & 62.5 & $18 \cdot 5$ & 18.9 & 25782 & 45.5 & $21 \cdot 2$ & 33.4 & 17498 \\
\hline Yes & 49.9 & $14 \cdot 1$ & $36 \cdot 1$ & 4169 & 33.4 & 13.6 & 53.0 & 4219 \\
\hline \multicolumn{9}{|l|}{ Health practice } \\
\hline \multicolumn{9}{|l|}{ Current regular exercise } \\
\hline No & $62 \cdot 2$ & $18 \cdot 0$ & $19 \cdot 8$ & 22847 & $46 \cdot 8$ & $21 \cdot 1$ & $32 \cdot 1$ & 12917 \\
\hline Yes & $56 \cdot 1$ & 17.5 & $26 \cdot 4$ & 7104 & $37 \cdot 7$ & $17 \cdot 7$ & 44.6 & 8800 \\
\hline \multicolumn{9}{|l|}{ Current smoking } \\
\hline No & $61 \cdot 3$ & $17 \cdot 9$ & $20 \cdot 7$ & 27753 & $46 \cdot 3$ & $20 \cdot 0$ & 33.7 & 16616 \\
\hline Yes & 53.4 & $17 \cdot 6$ & $29 \cdot 0$ & 2198 & $36 \cdot 6$ & $19 \cdot 2$ & $44 \cdot 2$ & 7101 \\
\hline \multicolumn{9}{|l|}{ Current heavy alcohol drinker } \\
\hline No & $61 \cdot 8$ & $17 \cdot 7$ & 20.5 & 26094 & $45 \cdot 2$ & $19 \cdot 6$ & $35 \cdot 2$ & 14850 \\
\hline Yes & 53.7 & $19 \cdot 3$ & $27 \cdot 0$ & 3857 & 38.6 & $20 \cdot 0$ & 41.4 & 6867 \\
\hline \multicolumn{9}{|l|}{ Health conditions } \\
\hline ADL disability & & & & & & & & \\
\hline Non-disabled & 57.9 & $18 \cdot 8$ & 23.3 & 18842 & $40 \cdot 3$ & $19 \cdot 8$ & 39.9 & 16686 \\
\hline Disabled & $65 \cdot 6$ & $16 \cdot 4$ & 17.9 & 11109 & 52.4 & $19 \cdot 5$ & $28 \cdot 1$ & 5031 \\
\hline Cognitive impairment & & & & & & & & \\
\hline Unimpaired & $58 \cdot 1$ & $18 \cdot 7$ & 23.2 & 20440 & $40 \cdot 7$ & $19 \cdot 7$ & 39.6 & 18339 \\
\hline Impaired & $66 \cdot 4$ & $16 \cdot 2$ & $17 \cdot 4$ & 9511 & $56 \cdot 4$ & $19 \cdot 5$ & $24 \cdot 1$ & 3368 \\
\hline
\end{tabular}


could modulate the biochemical and physiological processes that lead to the initiation and propagation of carcinogenesis and $\mathrm{CVD}^{(2,52,53)}$. Although there are many speculated interpretations, the underlying mechanisms between tea consumption and subsequent mortality/health are not clear. Furthermore, because there are several types of tea and because tea consumption is largely influenced by a variety of cultural, social, psychological, behavioural, pathophysiological and environmental factors ${ }^{(54)}$, it is very difficult to disentangle the true underlying mechanism. Further research focusing on the mechanism between tea consumption and health/mortality is clearly warranted.

The significant association between frequency of tea consumption and all-cause mortality in both young and oldestold men but not in women is novel. This result is in line with some previous studies which found that tea consumption could reduce the risk of mortality due to CVD and Parkinson's disease in men but not in women ${ }^{5,18)}$. This may be because women have higher levels of oestrogen that maintain the sufficient amount of dopamine neurons in the brain ${ }^{(18,55,56)}$. Health behaviour may also influence the sex difference. Past research indicates that smoking could increase exchange rates in sister chromatid, yet green tea consumption could reduce such exchange rates ${ }^{(57)}$. In China, the proportion of smoking in old men is four times as high as in old women, which may cause men to have a relatively higher exchange rate in sister chromatid that may translate into a higher risk of illness for men than for women. Tea consumption among some of these male smokers may largely offset the potential harmful effects of smoking, which benefits their health and makes the protective effects of tea consumption more noticeable among men than among women. Previous studies ${ }^{(58,59)}$ have also suggested that there is a sex difference in biological or genetic response to antioxidant nutrients, which may result in a different reaction to flavonoids between men and women. Other factors such as differences in lifestyles that were not included in this analysis could be related to the sex difference in the tea and mortality association. We welcome further studies to verify our speculations and recommend that future prospective studies be designed with adequate power to clarify whether and why sex would modify the interplay between frequency of tea consumption and mortality.

One interesting finding is that baseline health did not play a significant role in mediating the associations between frequency of tea consumption and subsequent health and mortality. This is different from what has been found in most other research fields. For example, many social epidemiological studies focusing on associations between SES and mortality frequently find that baseline health greatly modifies the associations between SES and mortality ${ }^{(39,60)}$. This probably suggests that tea consumption has a robust direct association with mortality.

Unlike most previous studies which focused on a single dimension of health, we used several measures such as ADL disability, cognitive impairment, self-rated poor health and one comprehensive measure - the cumulative health DI. These indicators measure multidimensional domains of health. The cumulative health DI combines thirty-nine health indicators to better measure the overall health condition. 
Table 3. Relative hazards $(\mathrm{RH}) \ddagger$ of frequency of tea consumption on subsequent mortality: tea-mortality sample, the Chinese Longitudinal Healthy Longevity Survey (CLHLS) $1998-2005 \S \|$

\begin{tabular}{|c|c|c|c|c|c|c|c|c|c|}
\hline \multirow[b]{2}{*}{ Sequential model and covariates } & \multicolumn{3}{|c|}{$\begin{array}{c}\text { Age } 85+\text { years } \\
(\mathrm{RH})\end{array}$} & \multicolumn{3}{|c|}{$\begin{array}{c}\text { Age } 65-84 \text { years } \\
(\mathrm{RH})\end{array}$} & \multicolumn{3}{|c|}{$\begin{array}{c}\text { Age } 65+\text { years } \\
(\mathrm{RH})\end{array}$} \\
\hline & $\begin{array}{l}\text { Both sexes } \\
(n 21585)\end{array}$ & $\begin{array}{l}\text { Women } \\
(n \text { 13581) }\end{array}$ & $\begin{array}{c}\text { Men } \\
(n \text { 8004) }\end{array}$ & $\begin{array}{c}\text { Both sexes } \\
(n 10058)\end{array}$ & $\begin{array}{l}\text { Women } \\
(n \text { 4864) }\end{array}$ & $\begin{array}{c}\text { Men } \\
(n \text { 5194) }\end{array}$ & $\begin{array}{l}\text { Both sexes } \\
\text { (n } 31643)\end{array}$ & $\begin{array}{l}\text { Women } \\
(n 18445)\end{array}$ & $\begin{array}{c}\text { Men } \\
(n \text { 13 198) }\end{array}$ \\
\hline \multicolumn{10}{|l|}{ Some times $v$. seldom } \\
\hline Model I. Drinking tea plus demographics & 0.96 & 0.95 & 0.96 & $0.87^{\star}$ & 0.94 & $0.81^{*}$ & $0.95^{\star}$ & 0.95 & 0.94 \\
\hline Model II. Model I plus diet & 0.96 & 0.95 & 0.97 & $0.87^{\star}$ & 0.94 & $0.80^{\star \star}$ & $0.95^{\star}$ & 0.95 & $0.94 \dagger$ \\
\hline Model III. Model II plus health practice & 0.96 & 0.95 & 0.96 & $0.88^{\star}$ & 0.96 & $0.81^{*}$ & $0.95^{*}$ & 0.95 & 0.94 \\
\hline Model IV. Model I plus SES & 0.96 & 0.95 & 0.97 & $0.87^{\star}$ & 0.93 & $0.81^{*}$ & $0.95^{*}$ & 0.95 & 0.94 \\
\hline Model V. Model III plus SES & 0.96 & 0.95 & 0.96 & $0.87^{\star}$ & 0.95 & $0.81^{\star}$ & $0.95^{\star}$ & 0.95 & 0.94 \\
\hline Model VI. Model V plus deficits index & 0.96 & 0.95 & 0.98 & $0.88 \dagger$ & 0.96 & $0.81^{*}$ & $0.96 \dagger$ & 0.95 & 0.96 \\
\hline \multicolumn{10}{|l|}{ Almost daily $v$. seldom } \\
\hline Model I. Drinking tea plus demographics & $0.90^{\star \star \star}$ & 0.96 & $0.84^{\star \star \star}$ & $0.83^{\star \star}$ & 0.94 & $0.77^{\star \star \star}$ & $0.89^{* * *}$ & 0.96 & $0.82^{\star \star \star}$ \\
\hline Model II. Model I plus diet & $0.94^{\star *}$ & 0.99 & $0.86^{\star \star *}$ & $0.86^{\star}$ & 0.95 & $0 \cdot 80^{\star *}$ & $0.92^{\star \star}$ & 0.99 & $0.85^{\star \star *}$ \\
\hline Model III. Model II plus health practice & 0.96 & 1.01 & $0.91^{*}$ & $0.89^{*}$ & 0.98 & $0.83^{\star}$ & $0.95^{\star}$ & 1.01 & $0.89^{\star \star}$ \\
\hline Model IV. Model I plus SES & $0.92^{\star \star}$ & 0.97 & $0.86^{\star \star *}$ & $0.86^{\star \star}$ & 0.95 & $0.80^{\star \star}$ & $0.91^{\star \star *}$ & 0.97 & $0.85^{\star \star \star}$ \\
\hline Model V. Model III plus SES & 0.97 & 1.01 & $0.91^{*}$ & $0.90 \dagger$ & 0.97 & $0.85^{\star}$ & $0.96 \dagger$ & 1.01 & $0.90^{\star *}$ \\
\hline Model VI. Model V plus deficits index & 0.99 & 1.03 & $0.94 \dagger$ & 0.93 & 1.00 & $0.88 \dagger$ & 0.98 & 1.02 & $0.93^{*}$ \\
\hline \multicolumn{10}{|l|}{ Almost daily $v$. some times } \\
\hline Model I. Drinking tea plus demographics & $0.95 \dagger$ & 1.01 & $0.87^{\star \star}$ & 0.96 & 1.00 & 0.94 & $0.94^{\star}$ & 1.01 & $0.88^{\star \star}$ \\
\hline Model II. Model I plus diet & 0.98 & 1.05 & $0.90^{\star}$ & 1.00 & 1.01 & 1.01 & 0.97 & 1.04 & $0.91^{*}$ \\
\hline Model III. Model II plus health practice & 1.01 & 1.06 & 0.94 & 1.01 & 1.02 & 1.02 & 1.00 & 1.06 & 0.95 \\
\hline Model IV. Model I plus SES & 0.96 & 1.02 & $0.89^{*}$ & 0.99 & 1.01 & 0.98 & 0.96 & 1.01 & $0.90^{\star}$ \\
\hline Model V. Model III plus SES & 1.01 & 1.07 & 0.95 & 1.03 & 1.03 & 1.05 & 1.01 & 1.06 & 0.96 \\
\hline Model VI. Model V plus deficits index & 1.02 & 1.08 & 0.95 & 1.05 & 1.05 & 1.07 & 1.02 & 1.07 & 0.97 \\
\hline \multicolumn{10}{|c|}{ 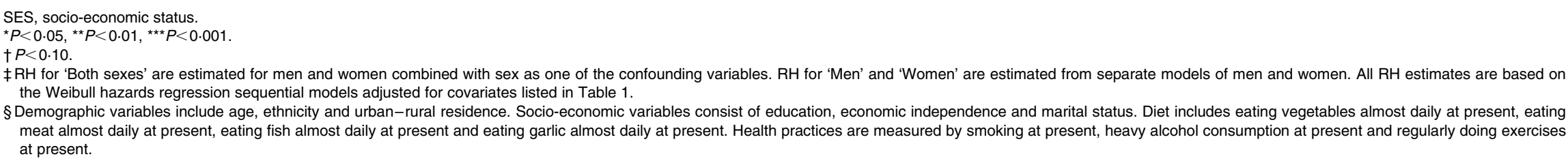 } \\
\hline
\end{tabular}


Table 4. OR of frequency of tea consumption on health conditions: tea-health sample, the Chinese Longitudinal Healthy Longevity Survey (CLHLS) $1998-2005 \ddagger \S$

\begin{tabular}{|c|c|c|c|c|c|c|c|c|c|}
\hline & \multicolumn{3}{|c|}{$\begin{array}{c}\text { Age } 85+\text { years } \\
(\mathrm{RH})\end{array}$} & \multicolumn{3}{|c|}{$\begin{array}{c}\text { Age } 65-84 \text { years } \\
\text { (RH) }\end{array}$} & \multicolumn{3}{|c|}{$\begin{array}{c}\text { Age } 65+\text { years } \\
(\mathrm{RH})\end{array}$} \\
\hline & $\begin{array}{c}\text { Both sexes } \\
(n 33617)\end{array}$ & $\begin{array}{l}\text { Women } \\
(n 21115)\end{array}$ & $\begin{array}{c}\text { Men } \\
\text { (n 12502) }\end{array}$ & $\begin{array}{l}\text { Both sexes } \\
(n 18051)\end{array}$ & $\begin{array}{l}\text { Women } \\
(n \text { 8836) }\end{array}$ & $\begin{array}{c}\text { Men } \\
(n \text { 9215) }\end{array}$ & $\begin{array}{l}\text { Both sexes } \\
\text { ( } n 51668)\end{array}$ & $\begin{array}{l}\text { Women } \\
\text { (n 29951) }\end{array}$ & $\begin{array}{c}\text { Men } \\
(n 21717)\end{array}$ \\
\hline \multicolumn{10}{|l|}{ General conditions } \\
\hline \multicolumn{10}{|l|}{ ADL disabled } \\
\hline Some times $v$. seldom & $0.76^{\star \star \star}$ & $0.76^{\star \star *}$ & $0.79^{\star \star}$ & $0.69^{* * *}$ & $0.69^{\star \star}$ & $0.67^{\star \star}$ & $0.75^{\star \star \star}$ & $0.75^{\star \star *}$ & $0.76^{\star \star \star}$ \\
\hline Almost daily $v$. seldom & $0.66^{\star \star \star}$ & $0.72^{\star \star \star}$ & $0.60^{\star \star \star}$ & $0.59^{\star * *}$ & $0.65^{\star \star \star}$ & $0.51^{\star \star \star}$ & $0.65^{\star \star \star}$ & $0.71^{* * *}$ & $0.58^{\star \star \star}$ \\
\hline Almost daily $v$. some times & $0 \cdot 87^{\star \star}$ & 0.95 & $0 \cdot 76^{\star \star}$ & 0.84 & 0.94 & $0.76 \dagger$ & $0.86^{\star \star \star}$ & 0.95 & $0.76^{\star \star \star}$ \\
\hline \multicolumn{10}{|l|}{ Cognitive impaired } \\
\hline Some times $v$. seldom & $0.72^{\star \star \star}$ & $0.74^{\star \star \star}$ & $0 \cdot 70^{\star \star \star}$ & 0.88 & 0.89 & 0.82 & $0 \cdot 75^{\star \star \star}$ & $0.75^{\star \star \star}$ & $0.73^{\star \star \star}$ \\
\hline Almost daily $v$. seldom & $0.71^{\star \star \star}$ & $0.78^{\star \star \star}$ & $0.63^{\star \star \star}$ & $0.67^{\star \star \star}$ & $0.71^{\star}$ & $0.56^{\star \star \star}$ & $0.71^{\star \star \star}$ & $0.77^{\star \star \star}$ & $0.62^{\star \star \star}$ \\
\hline Almost daily $v$. some times & 0.99 & 1.06 & 0.90 & $0.75^{\star}$ & 0.81 & $0.67^{\star}$ & 0.95 & 1.03 & $0.85^{\star}$ \\
\hline \multicolumn{10}{|l|}{ Self-report poor health } \\
\hline Some times $v$. seldom & $0 \cdot 68^{\star \star \star}$ & $0.69^{\star \star *}$ & $0 \cdot 65^{\star \star \star}$ & $0.69^{\star \star *}$ & $0.72^{\star \star}$ & $0.63^{* \star \star}$ & $0 \cdot 68^{\star \star *}$ & $0.69^{\star \star *}$ & $0.64^{\star \star \star}$ \\
\hline Almost daily $v$. seldom & $0.76^{\star \star \star}$ & $0 \cdot 87^{\star \star}$ & $0.61^{\star \star \star}$ & $0.75^{\star \star *}$ & $0.79^{\star \star}$ & $0.69^{\star \star \star}$ & $0.75^{\star \star \star}$ & $0.85^{\star \star *}$ & $0.64^{\star \star \star}$ \\
\hline Almost daily $v$. some times & $1 \cdot 12^{*}$ & $1 \cdot 25^{\star \star \star}$ & 0.95 & 1.09 & $1 \cdot 10$ & 1.09 & $1 \cdot 12^{\star \star}$ & $1 \cdot 22^{\star \star *}$ & 1.01 \\
\hline \multicolumn{10}{|c|}{ High deficit index (i.e. poor condition) } \\
\hline Some times $v$. seldom & $0.86^{\star \star}$ & 0.91 & $0.78^{\star \star}$ & $0.76^{\star}$ & $0.76 \dagger$ & 0.76 & $0.85^{\star \star}$ & $0.88^{*}$ & $0.78^{\star \star}$ \\
\hline Almost daily $v$. seldom & $0.77^{\star \star \star}$ & $0 \cdot 85^{\star \star}$ & $0 \cdot 68^{\star \star \star}$ & $0.63^{\star \star *}$ & $0.67^{\star}$ & $0.54^{\star \star \star}$ & $0.75^{\star \star \star}$ & $0.82^{\star \star *}$ & $0.64^{\star \star \star}$ \\
\hline Almost daily $v$. some times & $0.90 \dagger$ & 0.93 & 0.87 & 0.80 & 0.94 & $0.71 \dagger$ & $0.88^{*}$ & 0.93 & $0.83^{\star}$ \\
\hline \multicolumn{10}{|l|}{ Specific conditions } \\
\hline \multicolumn{10}{|l|}{ Suffering from CVD } \\
\hline Some times $v$. seldom & 0.96 & 1.09 & $0.78 \dagger$ & $0.73^{\star \star}$ & $0.64^{\star \star}$ & 0.78 & $0.86^{\star \star}$ & 0.90 & $0.78^{\star}$ \\
\hline Almost daily $v$. seldom & $0.82^{*}$ & 0.88 & $0.73^{*}$ & $0.61^{\star \star \star}$ & $0.50^{\star \star \star}$ & $0.63^{\star \star}$ & $0.72^{\star \star \star}$ & $0.71^{\star \star}$ & $0.68^{\star \star \star}$ \\
\hline Almost daily $v$. some times & 0.85 & 0.81 & 0.93 & 0.84 & 0.79 & 0.81 & $0.84^{*}$ & $0.79 \dagger$ & 0.88 \\
\hline
\end{tabular}

$\mathrm{RH}$, relative hazards; $\mathrm{ADL}$, activities of daily living.

${ }^{*} P<0.05,{ }^{* *} P<0.01,{ }^{* * *} P<0.001$

$\dagger P<0.10$.

‡OR for 'Both sexes' are estimated for men and women combined, with sex as one of the confounding variables. OR for 'Men' and 'Women' are estimated from separate models of Men and Women. All OR estimates are based on multilevel multiple logistic regressions adjusted for all covariates listed in Table 1 simultaneously.

$\S$ Df of all models for men and women separately is 15 , while the corresponding number for both sexes is 16 . 
More importantly, we further controlled for numerous covariates including demographics, SES, diet and health practice. We believe that this approach somewhat improves robustness in addressing the overall association between tea consumption and health, since researchers have frequently been challenged by residual confounders and co-morbidities.

Several limitations of this study should be taken into account when interpreting the results. First, the data on frequency of tea consumption in the CLHLS were self-reported. Although subjective evaluation of frequency of tea consumption is likely to be important and valid, this type of measure is not standardised, which may limit comparability with other studies. Second, the measurement error for this self-reported frequency of tea consumption may be a concern, although there is little concern about the consistency of such a measurement in the findings because our results are based on the cohort study. Biases may also be introduced due to cognitive problems of some respondents. However, such biases should not be large because a proxy was used when the respondents were not able to answer questions and because the accuracy of proxy answers for factual questions among old adults is quite $\operatorname{good}^{(24)}$. Third, in contrast to previous studies that were based on more detailed data on tea consumption, the present study examined very basic patterns of frequency of tea consumption among Chinese elders. More detailed questions, including data on quantity, density or type of tea consumed by older adults, would be informative. Fourth, it is very common for elderly people to take multivitamins and supplements in their daily life. Because of the unavailability of data, we were unable to control these confounding factors. Furthermore, our factors on diet and smoking are limited. These omissions may introduce some biases in our results. A couple of questions on daily multivitamins/supplements intake and diet were added in the 2008 wave and 2011 wave. We will conduct additional research once the data are available. Finally, there are about $20 \%$ of respondents who were lost to follow-up. This loss to follow-up may bias the results

It must be emphasised that the observational methods utilised in this study can only address associations between frequency of tea consumption and health and mortality. Thus, we can make no definitive claims about causality or the direction of association. However, we believe that the association is mainly from tea consumption to health/mortality for several reasons. First, we did not find any study to indicate that elders change their tea consumption habits in response to changes in health conditions, although type of food intake habits may change $^{(61)}$. Second, supplementary analyses (available upon request) found that health status at an earlier wave has little predictive power in predicting frequency of tea consumption at a later wave. Thus, we anticipate that reverse causality bias of health influencing tea consumption is mild or moderate.

In spite of these shortcomings, we have extended the existing research by providing new estimates of frequency of tea consumption and its associations with health and mortality among a unique, large sample of old adults from a developing country where the population of elders is growing and individual resources available to improve health and survival are lacking. The results of this study hence help us to understand the age and sex patterns of frequency of tea consumption and their associations with mortality and health status among exceptionally long-living adults.

\section{Acknowledgements}

The present study is based on a publicly available data set of the Chinese Longitudinal Healthy Longevity Survey (CLHLS) at Duke University, Durham, NC, USA. The CLHLS was supported by the National Institute on Aging (R01 AG023627-01) (Yi Zeng, principal investigator), the United Nations Population Fund (UNFPA), the China Natural Science Foundation, the China Social Sciences Foundation, and the Hong Kong Research Grants Council, and the Max Planck Institute for Demographic Research. J. S. is supported by Agency for Healthcare Research and Quality (AHRQ) training grant T32HS000079. The contributions of the authors to this study were as follows: L. Q. conducted the analysis and drafted the paper. J. S. drafted and revised the paper. D. G. initiated and designed the study, supervised the analysis, drafted and revised the paper. The authors declare that there are no conflicts of interest.

\section{References}

1. Henderson L, Gregory J \& Swan G (2002) National Diet and Nutrition Survey: Adults aged 19 to 64 years, vol. 2: Energy, Protein, Fat and Carbohydrate Intake. London: The Stationery Office.

2. Clement Y (2009) Can green tea do that? A literature review of the clinical evidence. Prev Med 49, 83-87.

3. Inoue M, Tajima K, Hirose K, et al. (1998) Tea and coffee consumption and the risk of digestive tract cancers: data from a comparative case-referent study in Japan. Cancer Causes Control 9, 209-216.

4. Iwai N, Ohshiro H, Kurozawa Y, et al. (2002) Relationship between coffee and green tea consumption and all-cause mortality in a cohort of a rural Japanese population. J Epidemiol 12, 191-198.

5. Nakachi K, Matsuyama S, Miyake S, et al. (2000) Preventive effects of drinking green tea on cancer and cardiovascular disease: epidemiological evidence for multiple targeting prevention. Biofactors 13, 49-54.

6. Nakachi K, Eguchi H \& Imai K (2003) Can teatime increase one's lifetime? Ageing Res Rev 2, 1-10.

7. Wu AH, Yu MC, Tseng CC, et al. (2003) Green tea and risk of breast cancer in Asian Americans. Int J Cancer 106 $574-579$

8. Kuriyama S, Shimazu T, Ohmori K, et al. (2006) Green tea consumption and mortality due to cardiovascular disease, cancer, and all causes in Japan: the Ohsaki Study. JAMA 296, 1255-1265.

9. Arab L, Liu W \& Elashoff D (2009) Green and black tea consumption and risk of stroke: a meta-analysis. Stroke $\mathbf{4 0}$, $1786-1792$

10. Gardner EJ, Ruxton CHS \& Leeds AR (2007) Black tea helpful or harmful? A review of the evidence. Eur J Clin Nutr 61, 3-18.

11. Hoshiyama Y, Kawaguchi T, Miura Y, et al. (2002) A prospective study of stomach cancer death in relation to green tea consumption in Japan. Br J Cancer 87, 309-313.

12. Li Q, Kakizaki M, Kuriyama S, et al. (2008) Green tea consumption and lung cancer: the Ohsaki Study. Br J Cancer 99, 1179-1184. 
13. Imai K, Suga K \& Nakachi K (1997) Cancer-preventive effects of drinking green tea among a Japanese population. Prev Med 26, 769-775.

14. Ide R, Fujino Y, Hoshiyama Y, et al. (2007) A prospective study of green tea consumption and oral cancer incidence in Japan. Ann Epidemiol 17, 821-826.

15. Sasazuki S, Inoue M, Hanaoka T, et al. (2004) Green tea consumption and subsequent risk of gastric cancer by site: the JPHC Study. Cancer Causes Control 15, 483-491.

16. Sasazuki S, Kodama H, Yoshimasu K, et al. (2000) Relation between green tea consumption and the severity of coronary atherosclerosis among Japanese men and women. Ann Epidemiol 10, 401-408.

17. Lee JE, Hunter DJ, Spiegelman D, et al. (2007) Intakes of coffee, tea, milk soda and juice and renal cell cancer in a pooled analysis of 13 prospective studies. Int $J$ Cancer 121, 2246-2253.

18. Ascherio A, Weisskopf MG, O'Reilly EJ, et al. (2004) Coffee consumption, gender and Parkinson's disease mortality in the Cancer Prevention Study II Cohort: the modifying effects of estrogen. Am J Epidemiol 160, 977-984.

19. Yang G, Shu XO, Li H, et al. (2007) Prospective cohort study of green tea consumption and colorectal cancer risk in women. Cancer Epidemiol Biomarkers Prev 16, 1219-1223.

20. Rimm EB \& Stampfer MJ (2004) Diet, lifestyle, and longevity - the next steps? JAMA 292, 1490-1492.

21. Thompson ME, Fong GT, Hammond D, et al. (2006) Methods of the International Tobacco Control (ITC) four country survey. Tobacco Control 15, Suppl. III, iii12-iii18.

22. U.S. Census Bureau (2002) Survey Income and Program Participation. http://www.census.gov/sipp/

23. Gu D (2008) General data assessment of the Chinese Longitudinal Healthy Longevity Survey in 2002. In Healthy Longevity in China: Demographic, Socioeconomic, and Psychological Dimensions, pp. 38-59 [Y Zeng Y, DL Poston, DA Vlosk and D Gu, editors]. Dordrecht: Springer Publisher.

24. Herzog AR \& Rodgers WL (1992) The use of survey method in research on older Americans. In The Epidemiologic Study of the Elederly, pp. 60-90 [RB Wallace and RF Woolson, editors]. New York, NY: Oxford University Press.

25. Gu D \& Dupre ME (2008) Assessment of reliability of mortality and morbidity in the 1998-2002 CLHLS waves. In Healthy Longevity in China: Demographic, Socioeconomic, and Psychological Dimensions, pp. 99-115 [Y Zeng, DL Poston, DA Vlosk and D Gu, editors]. Dordrecht: Springer.

26. Katz S, Ford AB, Moskowitz RW, et al. (1963) Studies of illness in the aged. The index of ADL: a standardized measure of biological and psychosocial function. JAMA $\mathbf{1 8 5}$, 914-919.

27. Folstein MF, Folsein SE, McHugh RR, et al. (1975) "MiniMental state": a practical method for grading the cognitive state of pattern for clinician. J Psychol Res 12, 189-198.

28. Zeng Y, Vaupel JW, Xiao Z, et al. (2002) Sociodemographic and health profiles of oldest-old in China. Popul Dev Rev 28, 251-273.

29. Zhang $Z$ (2006) Gender differentials in cognitive impairment and decline of the oldest old in China. J Gerontol B Psychol Sci Soc Sci 61, S107-S115.

30. Abellan van Kan G, Rolland Y, Berhman H, et al. (2008) The I.A.N.A. task force on frailty assessment of older people in clinical practice. J Nutr Health Aging 12, 29-37.

31. Bergman H, Ferrucci L, Guralnik J, et al. (2007) Frailty: an emerging research and clinical paradigm - issues and controversies. J Gerontol A Biol Sci Med Sci 62, 731-737.
32. Gu D, Dupre ME, Sautter J, et al. (2009) Frailty and mortality among Chinese at advanced ages. J Gerontol B Psychol Sci Soc Sci 64B, 279-289.

33. Kulminski A, Yashin A, Ukraintseva S, et al. (2006) Accumulation of heath disorders as a systemic measure of aging: findings from the NLTCS data. Mech Ageing Dev 127, $840-848$.

34. Mitnitski AB, Song X, Skoog I, et al. (2005) Relative fitness and frailty of elderly men and women in developed countries and their relationship with mortality. J Am Geriatr Soc 35, 2184-2189.

35. Goggins WB, Woo J, Sham A, et al. (2005) Frailty index as a measure of biological age in a Chinese population. J Gerontol A Biol Sci Med Sci 60, M1046-M1051.

36. Gu D (2009) The validity of health deficit index among Chinese old adults. Popul Eco 5, 52-57.

37. Gu D, Zhang Z \& Zeng Y (2009) Access to healthcare services makes a difference in healthy longevity among older Chinese adults. Soc Sci Med 68, 210-219.

38. Ferrucci L, Turchi A, Fumagallo S, et al. (2003) Sex-related differences in the length of disability prior to death in older persons. Aging Clin Exp Res 15, 310-314.

39. Liang J, Bennett J, Sugisawa H, et al. (2003) Gender differences in old age mortality: roles of health behavior and baseline health status. J Clin Epidemiol 56, 572-582.

40. Strawbridge WJ, Shema SJ, Cohen RD, et al. (2001) Religious attendance increases survival by improving and maintaining good health behaviors, mental health, and social relationships. Ann Behav Med 23, 68-74.

41. Stuck AE, Walthert JM, Nikolaus T, et al. (1999) Risk factors for functional status decline in community-living elderly people: a systematic literature review. Soc Sci Med 48, 445-489.

42. Hayward MD \& Pienta AM (1997) Inequality in men's mortality: the socioeconomic status gradient and geographic context. J Health Soc Behav 38, 313-330.

43. Hwang H \& Tajkane Y (2004) A multivariate reduced-rank growth curve model with unbalanced data. Psychometrika 69, 65-79.

44. Allison PD (2002) Missing Data. Thousand Oaks, CA: Sage.

45. Landerman LR, Land KC \& Pieper CF (1997) An empirical evaluation of the predictive mean matching method for imputing missing values. Soc Methods Res 26, 3-33.

46. Winship C \& Radbill L (1994) Sampling weights and regression analysis. Soc Methods Res 23, 230-257.

47. Hertog MG, Sweetnam PM, Fehily AM, et al. (1997) Antioxidant flavonols and ischemic heart disease in a Welsh population of men: the Caerphilly Study. Am J Clin Nutr 65, 1489-1494.

48. Mojžišová G \& Kuchta M (2001) Dietary flavonoids and risk of coronary heart disease. Physiol Res 50, 529-535.

49. Weisburger JH \& Chung FL (2002) Mechanisms of chronic disease causation by nutritional factors and tobacco products and their prevention by tea polyphenols. Food Chem Toxicol 40, 1145-1154.

50. Aneja R, Odoms K, Denenberg AG, et al. (2004) Theaflavin, a black tea extract, is a novel anti-inflammatory compound. Crit Care Med 32, 2097-2103.

51. Ju J, Hong J, Zhou JN, et al. (2005) Inhibition of intestinal tumorigenesis in Apcmin/t mice by (-)-epigallocatechin-3gallate, the major catechin in green tea. Cancer Res $\mathbf{6 5}$, 10623-10631.

52. Dufresne CJ \& Farnworth ER (2001) A review of the latest findings on the health promotion properties of tea. $J$ Nutr Biochem 12, 404-421. 
53. Rietveld A \& Wiseman S (2003) Antioxidant effects of tea: evidence from human clinical trials. Am Soc Nutr Sci $\mathbf{1 3 3}$, 3285S-3292S.

54. Heiss ML \& Heiss RJ (2007) The Story of Tea: A Cultural History and Drinking Guide. Berkeley, CA: Ten Speed Press.

55. Hercberg S, Galan P, Preziosi P, et al. (2004) The SU.VI.MAX Study: a randomized, placebo-controlled trial of the health effects of antioxidant vitamins and minerals. Arch Intern Med 164, 2335-2343.

56. Snel J, Koppes LLJ \& Twisk JW (2009) Sensitivity to coffee and subjective health. Act Nerv Super Rediviva 51, 61-68.

57. Shim JS, Kang MH, Kim YH, et al. (1995) Chemopreventive effect of green tea (Camellia sinensis) among cigarette smokers. Cancer Epidemiol Biomarkers Prev 4, 387-391.
58. Higdon JV \& Frei B (2005) Is there a gender difference in the effect of antioxidants on cancer risk? Br J Nutr 94, 139-140

59. Waters DJ, Chiang EC, Cooley DM, et al. (2004) Making sense of sex and supplements: differences in the anticarcinogenic effects of selenium in men and women. Mutat Res $\mathbf{5 5 1}$ 91-107.

60. Feinglass J, Lin S, Thompson J, et al. (2007) Baseline health, socioeconomic status, and 10-year mortality among older middle-aged Americans: findings from the health and retirement study, 1992-2002. J Gerontol B Psychol Sci Soc Sci 62 , S209-S217.

61. Boedhi-Darmojo R (2002) Trends in dietary habits of the elderly: the Indonesian case. Asia Pacific J Clin Nutr 11, $351-354$ 